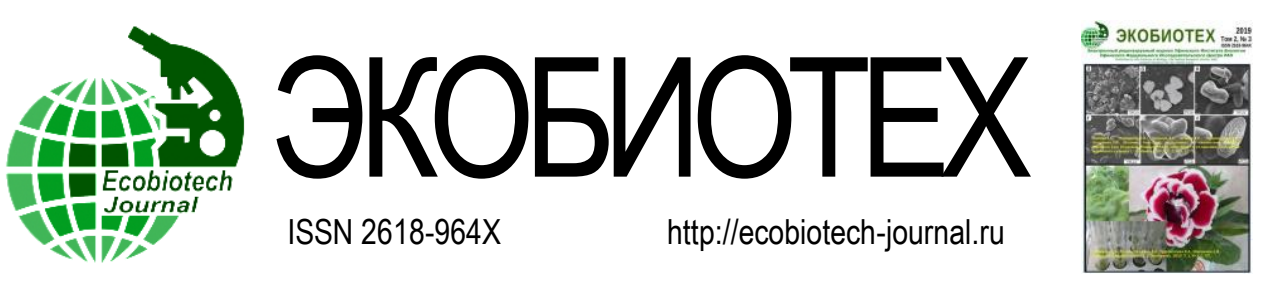

\author{
МОРФОЛОГИЧЕСКИЕ СВОЙСТВА ПОЧВ \\ АРХЕОЛОГИЧЕСКИХ ПАМЯТНИКОВ Г. УФЫ \\ (РЕСПУБЛИКА БАШКОРТОСТАН) \\ Сулейманов Р.P.1,2, Кунгурцев А.Я.2,3, \\ Проценко А.С. ${ }^{4}$, Шутелева И.А. ${ }^{5}$, \\ Щербаков Н.Б. ${ }^{5}$ \\ 1 Уфимский Институт биологии Уфимского федерального \\ исследовательского центра РАН, Уфа \\ 2 Башкирский государственный университет, Уфа \\ з Уральский федеральный университет, Екатеринбург \\ 4 Республиканский историко-культурный \\ музей-заповедник «Древняя Уфа», Уфра \\ ${ }^{5}$ Башкирский государственный \\ педагогический университет, Уфа \\ E-mail: soils@mail.ru
}

В работе приводятся результаты морфологического описания почвенного покрова двух археологических памятников, расположенных в центральной части г. Уфы (Республика Башкортостан). Показано, что в условиях древнего поселения «Городище Уфа-IІ» жизнедеятельность древнего человека привела к формированию культурных отложений, состоящих из перемешанных различных горизонтов фоновой природной почвы, слагающих данную территорию и археологических артефактов (фрагменты костей, древесные угли, фрагменты керамики). Мощность культурных слоев местами достигает 4 метров. В условиях древних захоронение «Ново-Уфимского могильника» погребенные почвы практически сохранили свое природное сложение (в них только обнаруживаются некоторые археологические артефакты), которые перекрыты горизонтом Урбик мощностью до 35 см, формирование которого происходило с середины XIX века и по настоящее время.

Ключевые слова: почвенный покров, археологический памятник, морфологические свойства почв

\section{MORPHOLOGICAL PROPERTIES OF SOILS OF ARCHAEOLOGICAL MONUMENTS OF UFA CITY (REPUBLIC OF BASHKORTOSTAN)}

\section{Suleymanov R.R. ${ }^{1,2}$, Kungurtsev A.Ya. ${ }^{2,3}$, Protsenko A.S. ${ }^{4}$, Shuteleva I.A. ${ }^{5}$, Shcherbakov N.B. ${ }^{5}$}

1 Ufa Institute of Biology of the Ufa Federal Research Centre of the Russian Academy of Sciences, Ufa

2 Bashkir State University, Ufa

3 Ural Federal University, Yekaterinburg

${ }^{4}$ National Historical and Cultural

Museum-Reserve «Ancient Ufa»

${ }^{5}$ Bashkir State Pedagogical

University n. a. M. Akmulla, Ufa

E-mail: soils@mail.ru

The work presents the results of a morphological description of the soil cover of two archaeological sites located in central part of Ufa city (Republic of Bashkortostan). It is shown that in the conditions of ancient settlement «Settlement of Ufa-II» the vital activity of an ancient person led to the formation of cultural deposits. These deposits consist of mixed different horizons of the background natural soil, which composes this territory and archaeological artifacts (bone fragments, charcoal, ceramic fragments). The thickness of the cultural layers in some places reaches 4 meters. In the conditions of the ancient burial of the «New-Ufa burial ground», the buried soils have practically preserved their natural composition (they only contain some archaeological artefacts). Buried soils are covered by the Urbik horizon with a thickness of up to $35 \mathrm{~cm}$, the formation of which took place from the middle of the XIX century to the present.

Keywords: soil cover, archaeological site, morphological properties of soils

Поступила в редакичию: 3.09.2019

DOI: $10.31163 / 2618-964 X-2019-2-4-462-467$

В последнее время большое внимание уделяется изучению почвенного покрова урбанизированных территорий, поскольку почвы выполняют широкий спектр экологических функций в условиях интенсивной антропогенной нагрузки (почва как среда обитания и жизнедеятельности разнообразных форм жизни, обеспечение биологического и геологического круговорота веществ и энергии, осуществление санитарно-гигиенических и 
ландшафтно-эстетических функций) [Ashmore, Blackmore, 2008; Добровольский и др., 2012; Artmann, 2015; Blanchart et al., 2018].

В тоже время жизнедеятельность человека в пределах города способствует к изменению окружающей природной среды - меняется рельеф и гидрографическая сеть, идет смена растительных сукцессий, формируется специфический городской микроклимат, уничтожается или трансформируется почвенный покров. В результате чего антропогенное воздействие становится преобладающим над естественными природными факторами почвообразования, что в результате приводит к формированию в новых экологических условиях специфических почв и почвоподобных тел [Почва..., 1997].

Антропогенная трансформация почвенного покрова, способствующая формированию запечатанных и погребенных почв, предопределяет появление информационной функции почв. Данная функция позволяет «записывать» и сохранять в своем составе и свойствах свидетельства об условиях почвообразования. В тоже время в грунтовых толщах древних городищ и поселений, да и современных старых городов сохранились древние почвы, по которым можно судить о природной и антропогенной обстановке того времени, когда они формировались. Эти «свидетельства» содержатся в виде различных минеральных и органических новообразований, почвенного гумуса, посмертных остатков растительных и животных организмов. Функция почв «запоминать» и сохранять свидетельства прошлого получила название в научной литературе как «Память почв». В последнее время информационные функции почв находят все более широкое применение в особом направлении почвоведения - палеопочвоведении (историческое почвоведение) или археологическом почвоведение [Scudder et al., 1996; Демкин, 1997; Почва..., 1997; Память..., 2008; Macphail, 2008; Rothschild, di Zerega, 2008; Добровольский и др., 2012; Feinman, 2015; Li et al., 2018].

Так, например раскопки в центральной части Антверпена (Бельгия) выявили в погребенных почвенных горизонтах (760-970 гг. н.э.) хорошо сохранившиеся деревянные дорожки, заборы и многочисленные находки, часто связанные с кустарной деятельностью, в том числе обработкой костей, рогов и металла. В останках макрофауны преобладали кости домашнего скота и свиней, а также диких млекопитающих, в том числе благородных оленей, кабанов и бобров. Также микроморфологический анализ выявил культурный слой, состоящий из конского навоза, в состав которого также входили фрагменты листьев, травы, дерева, насекомых, что позволило определить типы лесов и растительности, окружавших город на тот момент времени [Crabtree et. al., 2017].

В Лиере (Бельгия) при изучении погребенных темных гуминовых слоев (XI-XV века н.э.), которые содержали больше органических веществ и антропогенных включений, было определено, что они образовались в результате интенсивной деятельности человека, ставшей свидетелем преобразования сельскохозяйственных земель в городское пространство [Wouters et al., 2017].

Исследования, проведенные в условиях городских поселений (XIV-XVI века н.э.) на тропических островах Танзании с использованием геохимических, геоархеологических, геофизических и археологических методов позволили определить условия окружающей среды острова и археологические отложения, а также выделить открытые пространства между зданиями [Sulas et al., 2017].

B pаботе G.L Zhang et al. [2007] показано, что почвы в городских районах часто искусственно формируются и сохраняются как культурные слои, в которых почвенные материалы смешиваются с артефактами. Вертикальное изменение свойств почвы означает 
историческое изменение человеческой деятельности, и, следовательно, городская почва может рассматриваться как запись истории городского развития. Изучение профиля городской почвы (Нанкин, Китай) позволило установить, что формирование культурного слоя началось около 1700 лет назад и продолжалось до недавнего времени. Все культурные слои выше первоначального лесса были сильно загрязнены свинцом с общим содержанием от 100 мг/кг до 1000 кг/кг. Высокое содержание свинца обусловлено древней плавкой руды различного назначения и использованием свинец-содержащих материалов для ремесленного производства.

Целью нашего исследования явилось морфологическое описание почвенного покрова двух археологических памятников (Уфа-ІІ и Ново-Уфимский могильник), расположенных на территории города Уфа (Республика Башкортостан).

Археологический памятник Городище Уфа-II находится в центре города, на участке ограниченном улицами Заки Валиди, Новомостовая, Пушкина и проспектом Салавата Юлаева. Согласно археологической датировке время функционирования памятника приходится на период I в. до н.э. - VII в. н.э., население которого было представлено бахмутинской, турбаслинской и кушнаренковской археологическими культурами [Мажитов и др., 2008]. Датировка методом радиоуглеродного анализа показала время в пределах первой половины II в. н.э. или до н.э. - второй половины VII в. н.э. [Levchenko, Sungatov, 2013].

Исследования проводились на левом краю оврага, по дну которого протекает ручей, впадающий в р. Белая. На обследованной территории мощность культурного слоя местами достигает 4 метров. Почвенный покров территории характеризуется сильной механической нарушенностью, в связи с чем, возникает затруднение идентификации генетических почвенных горизонтов, характерных для ненарушенных почв. В связи с этим, почвенные горизонты, отличающиеся по своим морфологическим свойствам, в данном случае были выделены как слои, приведем их морфологическое описание:

Слой 1, 0-50 см - неоднородно-окрашенный, серовато-коричневый, сухой, сильно перемешан, отходы строительного материала, битый кирпич, куски шифера, щебень, пересыпан песком и галькой, плотный.

Слой 2, 50-63 см - темно-серый, влажноватый, мелко-среднекомковатый, средний суглинок, плотный, включения гальки и щебня.

Слой 3, 63-67 см - светло-коричнево-рыжеватый, влажноватый, бесструктурный, супесчаный, включения гальки.

Слой 4, 67-80 см - неоднородно-окрашенный, цвет постепенно меняется от темносерого до светло-серого, влажноватый, мелко-среднекомковатый, легкий суглинок, включения фрагментов керамики, костей, древесного угля.

Слой 5, 80-101 см - темно-серый, влажноватый, мелко-среднепризматический, легкий суглинок, включения фрагментов керамики, костей, древесного угля.

Слой 6, 101-120 см - серовато-рыжий, влажный, крупнопризматический, легкий суглинок, легкий суглинок, включения керамики, фрагментов костей, древесного угля.

Слой 7, 120-177 см - коричнево-рыжеватый, влажный, крупнопризматический, легкий суглинок.

Слой 8, 177-190 см - светло-рыжий влажный бесструктурный песок.

Почва - Урбанозем на аллювиальных отложениях.

Анализ морфологических свойств почвы изученного участка показывает, что верхний слой 1 сформировался в результате жизнедеятельности современного человека, и большая 
часть, составляющая этот слой, представляет собой привнесенные извне строительные материалы и бытовой мусор, которые в некоторой степени были перемешаны с суглинками слоя 2. Формирование слоев 2 и 3 произошло в результате двух процессов - с одной стороны это антропогенная деятельность человека, с другой природные почвообразовательные процессы, однако отсутствие в этих слоях археологических артефактов не позволяет их отнести ко времени функционирования археологического памятника «Городище Уфа-II», т.е. их формирование произошло в более позднее время. Слои 4, 5, 6, и 7 сформировались во время непосредственного функционирования археологического памятника, от других слоев в первую очередь их отличает повышенное содержание валового фосфора (3727-4138 мг/кг почвы), при этом содержание гумуса, общего азота, подвижных форм фосфора и калия соответствует фоновым почвам (серые лесные почвы), слагающим Уфимский полуостров [Suleymanov et al., 2020]. В этих слоях также встречаются фрагменты керамики, костей и древесного угля. Слой 8 представляет собой рыхлую почвообразующую породу легкого механического состава, затронутою природными почвообразовательными процессами.

Ново-Уфимский могильник также находится в центр города, и расположен на пересечении улиц Заки Валиди и Гоголя. Данная территория начиная с 1852 года была занята постройками и огородами жителей города, в дальнейшем подвергалась активному антропогенному освоению с середины XIX века и до сегодняшних дней. Согласно археологической датировке погребения относятся ко II в. н.э. (кара-абызская археологическая культура). Датировка радиоуглеродным методом пока не проводилась.

Обследованная территория представляет собой выровненный участок местности, которая сильно захламлена, на поверхности строительный и бытовой мусор, местами сваленный в кучи. Приведем морфологическое описание почвенного профиля:

Урбик, 0-35 см. Неоднородно-окрашенный темно-серый сизовато-оливковый, тяжелосуглинитсый, включения обломков кирпичей, гальки, булыжников, щебня, древесных остатков и бытового мусора, переход к следующему горизонту резкий по цвету, структуре и гранулометрическому составу.

А1погребенный 35-46 см. Темно-серый, влажный, мелко-средне-ореховатый, среднесуглинистый, корни деревьев, включения углей и костей, переход постепенный.

$\mathrm{AB} \quad 46-53$ см. Серовато-бурый, влажный, средне-крупно-ореховатый, среднесуглинистый, легкая присыпка кремнезема на структурных отдельностях, корни деревьев, включения углей, переход постепенный.

В 53-72 см. Буровато-коричневый, пятна сероватых гумусовых потеков, влажный, средне-крупно-комковатый, тяжелосуглинистый, легкая присыпка кремнезема на структурных отдельностях, переход постепенный.

С 72-90 см. Рыжевато-коричневый, влажный, бесструктурный, тяжелосуглинистый, включения щебенки карбонатных пород и костей.

Почва - Урбанозем по темно-серой почве на делювии карбонатных пород.

Анализ морфологических свойств почвенного покрова показывает, что на исследованном участке на поверхности мощностью до 35 см сформировался урбанизированный горизонт, который состоит из смеси суглинка, глины, строительного и бытового мусора. Под урбанизированным горизонтом располагается погребенная темносерая почва, которая соответствует почвенному покрову Уфимского полуострова, сформировавшемуся в естественных природных условиях и сохранившемуся на сегодняшний день в нетронутом состоянии на территории некоторых парков и лесных массивов [Suleymanov et al., 2020]. Однако, обнаруженные включения в генетических 
горизонтах погребенной почвы (горизонты А1пог., АВ и В) (угли, кости, артефакты), а особенно наличие костей в почвообразующей породе (горизонт С) позволяет отнести его к горизонтам, на которые оказала влияние жизнедеятельность древнего человека.

Таким образом, проведенные исследования на территории археологического памятника «Городище Уфа-ІІ», показали, что жизнедеятельность древнего человека привела к формированию культурных отложений, состоящих из различных перемешанных горизонтов фоновой природной почвы, слагающих данную территорию и археологических артефактов (фрагменты костей, древесные угли, фрагменты керамики). Культурные слои по своему химическому составу характеризуются повышенным содержанием валового фосфора, а содержание гумуса, общего азота, подвижных форм фосфора и калия соответствует фоновым природным почвам. В среднем общая мощность культурного слоя археологического памятника «Городище Уфа-ІІ» в данном профиле составляет 110 см (слои № 4-7). Остальные перекрывающие их слои сформировались в более позднее время.

В условиях древних захоронение Ново-Уфимского могильника погребенные почвы практически сохранили свое природное сложение (в них только обнаруживаются некоторые археологические артефакты), которые перекрыты горизонтом Урбик мощностью до 35 см, формирование которого происходило с середины XIX века и по настоящее время.

\section{СПИСОК ЛИТЕРАТУРЫ}

1. Демкин В.А. Палеопочвоведение и археология: интеграция в изучении природы и общества. Пущино. 1997. 214 с.

2. Добровольский Г.В., Куст Г.С., Чернов И.Ю., Добровольская Т.Г., Лысак Л.В., Андреева О.В., Степанов А.Л., Ковалева Н.О., Макеев А.О., Федотов Г.Н., Шалаев В.С., Соколов М.С., Розов С.Ю., Смагин А.В., Ковалев И.В., Медведева О.Е., Бессонова Е.А., Попова Л.В., Рыхликова М.Е., Рахлеева А.А., Мартыненко И.А. Почвы в биосфере и жизни человека: монография. ФГБОУ ВПО МГУЛ Москва, 2012. 584 с.

3. Мажитов Н.А., Сунгатов Ф.А., Султанова А.Н. Сокровища древней Уфы. Уфа, 2008. $112 \mathrm{c}$.

4. Память почв: почва как память биосферно - геосферно - антропогенных взаимодействий / Отв. ред. В.О. Таргульян, С.В. Горячкин. М.: Издательство ЛКИ, 2008. 692 c.

5. Почва. Город. Экология / Под. ред. Г.В. Добровольского. М.: Фонд «За экономическую грамотность», 1997. $320 \mathrm{c.}$

6. Artmann M. Managing urban soil sealing in Munich and Leipzig (Germany) - From a wicked problem to clumsy solutions // Land Use Policy. 2015. Vol. 46. P. 21-37. DOI: 10.1016/j.landusepol.2015.02.004

7. Ashmore W., Blackmore C. Landscape Archaeology / Editor(s): Deborah M. Pearsall. In Encyclopedia of Archaeology. Academic Press, 2008. P. 1569-1578. DOI: 10.1016/B978$\underline{012373962-9.00170-9}$

8. Blanchart A., Séré G., Johan C., Gilles W., Stas M., Consalès J.N., Morel J.L., Schwartz C. Towards an operational methodology to optimize ecosystem services provided by urban soils // Landscape and Urban Planning. 2018. Vol. 176. P. 1-9. DOI: 10.1016/j.landurbplan.2018.03.019

9. Crabtree P.J., Reilly E., Wouters B., Devos Y., Bellens T., Schryvers A. Environmental evidence from early urban Antwerp: New data from archaeology, micromorphology, 
macrofauna and insect remains // Quaternary International. 2017. Vol. 460. P. 108-123. DOI: 10.1016/j.quaint.2017.08.059

10. Feinman G.M. Settlement and Landscape Archaeology / Editor(s): James D. Wright. International Encyclopedia of the Social \& Behavioral Sciences (Second Edition). Elsevier, 2015. P. 654-658. DOI: 10.1016/B978-0-08-097086-8.13041-7

11. Levchenko V.A., Sungatov F.A. Building the radiocarbon chronology for the archaeological site Ufa-II, Bashkortostan, Russia: is this the elusive «Bashkort» of medieval sources? // Radiocarbon. 2013. Vol. 55. № 2/3. P. 1278-1285.

12. Li M., Fang H., Zheng T.X., Rosen A., Wright H., Wright J., Wang Y. Archeology of the Lu City: Place memory and urban foundation in Early China // Archaeological Research in Asia. 2018. Vol. 14. P. 151-160. DOI: 10.1016/j.ara.2017.02.006

13. Macphail R.I. Soils and Archaeology / Editor(s): Deborah M. Pearsall. In Encyclopedia of Archaeology. New York. Academic Press. 2008. P. 2064-2072. DOI: 10.1016/B978012373962-9.00290-9

14. Rothschild N.A., di Zerega W.D. Urban Archaeology / Editor(s): Deborah M. Pearsall. In Encyclopedia of Archaeology. New York. Academic Press. 2008. P. 2164-2171. DOI: 10.1016/B978-012373962-9.00313-7

15. Scudder S.J., Foss J.E., Collins M.E. Soil Science and Archaeology / Editor(s): Donald L. Sparks. Advances in Agronomy. Academic Press. 1996. Vol. 57. P. 1-76. DOI: $10.1016 / \mathrm{S} 0065-2113(08) 60922-0$

16. Sulas F., Fleisher J., Wynne-Jones S. Geoarchaeology of urban space in tropical island environments: Songo Mnara, Tanzania // Journal of Archaeological Science. 2017. Vol. 77. P. 52-63. DOI: 10.1016/j.jas.2016.06.002

17. Suleymanov A.R., Suleymanov R.R., Abakumov E.V., Nigmatullin A.F., Khamidullin R.A. Soil-Ecological Assessment of the M.I. Kalinin Park Ufa City, Russia. In: Vasenev V., Dovletyarova E., Cheng Z., Valentini R., Calfapietra C. (eds) Green Technologies and Infrastructure to Enhance Urban Ecosystem Services. SSC 2018. Springer Geography. Springer, Cham, 2020. P. 18-28. DOI: 10.1007/978-3-030-16091-3_4

18. Wouters B., Devos Y., Milek K., Vrydaghs L., Bartholomieux B., Tys D., Moolhuizen C., van Asch N. Medieval markets: A soil micromorphological and archaeobotanical study of the urban stratigraphy of Lier (Belgium) // Quaternary International. 2017. Vol. 460. P. 48-64. DOI: $10.1016 /$ j.quaint.2017.03.002

19. Zhang G.L., Yang F.G., Zhao W.J., Zhao Y.G., Yang J.L., Gong Z.T. Historical change of soil $\mathrm{Pb}$ content and $\mathrm{Pb}$ isotope signatures of the cultural layers in urban Nanjing // CATENA. 2007. Vol. 69. № 1. P. 51-56. DOI: 10.1016/j.catena.2006.04.013 